\title{
Illusions of empowerment? Questioning policy and practice of community forestry in Kenya
}

\author{
$\underline{\text { Susan W. Chomba }}^{1,2}$ Iben Nathan $^{1}$, $\underline{\text { Peter A. Minang }}^{2,3}$ and Fergus Sinclair $^{3,4}$
}

\begin{abstract}
The extent to which community forestry $(\mathrm{CF})$ contributes to empowerment of local communities remains hotly contested. We develop a unified theory of empowerment at the intersection of asset-based agency and institution-based opportunity and apply it to examine the extent to which the implementation of $\mathrm{CF}$ has led to local empowerment. Our empirical data are drawn from review of national level policies and a field study of Ngare Ndare Community Forest Association (CFA) in Kenya. We investigated what types of powers were transferred to the local level, how representative the local institution was of the local community, and how its formation and composition affected the empowerment of socially and economically differentiated groups, with competing claims over the forest resource. We found that national forest policies and actors transferred minimal powers that enabled local communities to execute forest protection and conservation roles, while maintaining legislative powers and control of economic benefits centrally; and, that representation within the CFA was highly skewed in favor of small and already powerful local elites. We discuss the findings in the light of the literature on empowerment to develop insights about how to more effectively manage processes to empower local communities through appropriately representative institutions.
\end{abstract}

Key Words: community forestry; empowerment; Kenya; representation

\section{INTRODUCTION}

Governments own and manage more than $80 \%$ of the world's forests (FAO 2010) but a trend toward community-based forest management (CBFM) has gained momentum over the past 30 years (Agrawal et al. 2008, FAO 2010). Local communities and forest-user groups now govern an estimated 200 million ha of forests (Sandbrook et al. 2010). A key objective of CBFM is to devolve power in forest management from central levels of governments to local communities, thereby empowering communities to make decisions about the resources that are important for their livelihood (Kellert et al. 2000, Blaikie 2006). The basic principles of CBFM include public participation and democratic decision-making processes (Borrini-Feyerabend et al. 2004). These principles reflect global conventions on the environment and human rights such as the Rio Declaration on Environment and Development; the Statement of Forest Principles, and Agenda 21, that couple poverty reduction with sustainable natural resource management (UN 1992); the Aarhus Convention, which established rights of access to information, public participation in decision making, and access to environmental justice (UNECE 1998); the Millennium Development Goals (MDGs), and in particular goal number seven on ensuring environmental sustainability (UN 2000); and the UN Declaration on the Rights of Indigenous People with its emphasis on Free, Prior and Informed Consent (UN 2007). Taken together, these global declarations call for public participation and democratic decision making as prerequisites for effective environmental governance and sustainable development in the context of their contribution to universal human rights.

In the last few decades, natural resource governance has, both in theory and practice, witnessed a surge toward these global ideals of democracy and local enfranchisement (White and Martin 2002, Sandbrook et al. 2010). This paradigm shift has been associated with three main developments: (i) mounting evidence that traditional practices of managing natural resources do not necessarily lead to the "tragedy of the commons" (Hardin 1968) but can achieve positive outcomes for biodiversity conservation, ecosystem resilience, and improvement of rural livelihoods (Ostrom 1990); (ii) the realization that hierarchical, single agency, top down management systems are not very effective at curbing deforestation (White and Martin 2002, Berkes 2009); (iii) desire to exercise justice, especially after recognizing that exclusion of indigenous people and other members of local communities from forest management discriminates against their traditional and globally recognized human rights (Brosius et al. 1998, Larson 2005).

Although the rationale for CBFM appears compelling, many scholars have observed that its practical implementation often falls short of achieving the intended goals, particularly in terms of local empowerment. Various reasons have been suggested for this. First, it has become increasingly evident that reconciling multiple objectives of conservation, livelihoods, and governance can be daunting. As such, many cases of CBFM end up attaining, for instance, conservation goals at the expense of local empowerment (Kellert et al. 2000). The implication is that the three goals are not necessarily mutually reinforcing (Ribot et al. 2010). Second, a "community" comprises a complex set of actors, with different social, economic, and political characteristics such as wealth, gender, age, ethnicity, and castes (Agrawal and Gibson 1999). These actors have different access to resources and power, as well as different interests in, and claims over, various environmental goods and services (Leach et al. 1999, Nygren 2000; Chomba et al., in press). A key question then arises around which of these actors are actually empowered when resources and decision-making powers are transferred to local institutions? Third, the implementation of CBFM usually involves a plethora of institutions at various levels who may all claim to represent the interests of local communities. These include local user groups, 
associations, government line ministries and representatives, civil society organizations, and other fluid forms of collective action. It is increasingly being realized that institutional arrangements most likely to deliver on CBFM goals are quite complex, not least because each of these institutional forms have their strengths and weaknesses in addressing the needs of the local people (Ribot 2004; Chomba et al., in press). Current debates on CBFM center on crucial questions of who should be empowered and how should they be empowered. What is the nature of powers that should be shared or transferred and which institutions can be considered representative of the diverse interests that pertain in any particular context?

\section{The history of CBFM in Kenya}

Debates around CBFM are a hot topic in Kenya because they resonate with a national process of devolution under the Constitution of 2010. The Government of Kenya formally introduced CBFM in 2005 through the Forest Act (GoK 2005). This Act provides for communities to participate in CBFM through the formation of community forest associations (CFAs). Article 46(1) states: "A member of a forest community may, together with other members or persons resident in the area, register a community forest association under the Societies Act... an association registered under subsection (1) may apply to the Director (of Kenya Forestry Service-KFS) for permission to participate in the conservation and management" (GoK 2005:38). CFAs are required to formulate forest management plans and sign management agreements with KFS as preconditions for participating in CBFM. By the year 2012, over 300 CFAs had been registered across the country and numerous others were in the process of registration (Mogoi et al. 2012). KFS also reported a rapid increase in signing management agreements with CFAs across the country by December 2014, where a total of 68 agreements had been signed (Standard Media 2015).

The Forest Act has been heralded as a radical shift away from former forest policies that were characterized by fierce state control and exclusion of local communities (World Bank 2007). This was largely because, prior to the introduction of CBFM, forest management in Kenya, particularly in gazetted ${ }^{[1]}$ forests, was founded on colonial antecedents of reservation and protection aimed at supplying wood for the colony (Thenya et al. 2008, Mugo et al. 2010). Designation of forest reserves, which occurred mostly in the colonial era (1895-1963), often involved displacement of local communities and/or their exclusion from access and usufruct rights to land and forests (Standing and Gachanja 2014; S. Chomba, J. Kariuki, J. F. Lund, and F. Sinclair, unpublished manuscript). Postcolonial governments continued these policies of exclusion, and deliberately used them to further their own political and economic gains (Thenya et al. 2008, Standing and Gachanja 2014).

In particular, the Moi era was characterized by appointment of political cronies to head the Forest Department, corruption, and plundering of forests, which resulted in great forest loss (Mugo et al. 2010, Njeru 2010). At this time, the Forest Department presided over double standards where logging concessions were awarded to large saw millers, owned by political elites, while small saw millers were banned (Standing and Gachanja 2014). Ironically, these large-scale excisions occurred at the time when the government was exercising strict restrictions of forest access by the rural poor. For instance, the shambaltaungya system, which had been established in the 1960 s to enable poor farmers to contribute to the establishment of forest plantations, while at the same time benefiting from farming amongst the young trees was discontinued under a departmental instruction in 1988 (Mogaka et al. 2001, as cited in Mugo et al. 2010). However, when it was in the interest of political elites, particularly during political elections, forests were used as patronage, awarded to squatters or fellow members of the elite in exchange for their political support (Klopp 2012, Standing and Gachanja 2014). Other forests were subject to World Bank and state sanctioned conversions under the infamous "Nyayo tea zones"[2] (Klopp 2012, Njeru 2013).

Pressure from civil societies and donors, bolstered by the global conventions mentioned above, prompted the radical shift in government rhetoric from state-centric to people-centric forms of forest management (Thenya et al. 2008). In 1991, the government launched the Kenya Forest Master Plan, which was a 25-year plan that embraced principles of sustainable forest management, and encouraged community participation on a trial basis. CBFM, also known as Participatory Forest Management (PFM) in Kenya, was then legally underpinned in the Forest Act, which was passed in 2005 and gazetted on 9 February 2007. The Forest Act also required the transformation of the Forest Department into the Kenya Forest Service (KFS), a semiautonomous agency with greater legislative and fiscal powers.

The Forest Act vested the role of empowerment of CFAs on KFS. Article 4(M) of the Forest Act states the function of KFS shall include "promoting the empowerment of associations and communities in the control and management of forests" (GoK 2005:11). Some of the key legislations enacted by KFS in conjunction with the then Ministry of Environment and Natural Resources (MENR) to facilitate community participation and empowerment were the PFM Rules and the PFM Guidelines (MENR 2007a,b). On representation, the PFM guidelines state that interested members of the community living adjacent to the forest must form CFAs; and that CFA leadership must be selected through a fair electoral process. The CFA leadership must also represent forest users and other stakeholders, as well as take into consideration gender and marginalized groups (MENR 2007a,b)

The Forest Act and its supporting legislation have now been functioning for some time (since 2007), and it is imperative to take stock of whether they meet their objectives of empowerment, i.e., have the administrative and policy reforms that have been enacted translated into any meaningful changes on the ground? Against this background, the aims of the present research are twofold: (i) to examine empowerment and representation under CBFM in the particular context of Kenya; (ii) to provide local lessons to inform national and global policies and current scholarly debates on CBFM. It does so first by developing a theoretical framework on empowerment and representation. It then uses the framework to interrogate two research questions: (i) What is the nature of powers that have actually been transferred to the CFAs in Kenya? (ii) To what extent can the CFAs be considered representative of the communities and what are the implications for community empowerment?

\section{Theory of empowerment}

There are variations in meaning and assessments of the concept of empowerment. On the one hand, empowerment indicates the 
ability of an individual or group to exercise agency, choice, selfdetermination, entitlement to make decisions, freedom, control, and ownership of their lives (Rowlands 1997, Alkire 2005). On the other hand, empowerment is perceived as making institutions, state and nonstate, more responsive and accountable to poor people (Ribot 2004, Narayan 2005). Thus the conceptualization of empowerment can be distinguished under two main schools of thought: one based on peoples' agency, choice, and the ability to control their own lives; and the second based on political and economic notions of making institutions more responsive to local people (Ibrahim and Alkire 2007). Here, we unite these two schools of thought by regarding empowerment as the intersection of "asset-based agency" with "institution-based opportunity structures" (Fig. 1). Clearly, asset-based agency will be important for institutional-based opportunity structures to function (Alsop et al. 2006, Ibrahim and Alkire 2007), because empowerment involves expanding assets and capabilities of poor people so that they can deliberate within institutions, that is, participate, negotiate, persuade, and hold institutions accountable (Narayan 2005).

Fig. 1. Empowerment as the intersection of asset-based agency and institution-based opportunity with transformative processes of democracy and transfer of powers, respectively. Agency is ultimately an attribute of individuals but tends to be applied to groups. Multiple, overlapping ways of grouping individuals may apply (hexagon labels are illustrative) and may be relevant to understanding how inclusive representation is of socially differentiated groups of actors, both descriptively and substantively. Democracy is seen as a critical means of achieving representation.

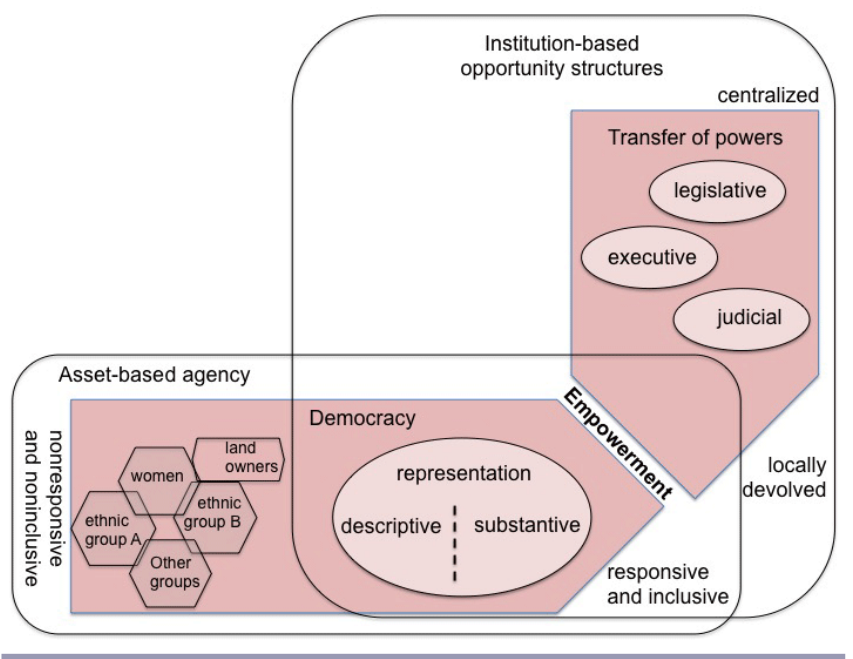

Scholars analyzing decentralized forest management have built on institutionalism to suggest that empowerment can result from transfer of various types of powers from higher to lower levels of governance in political and administrative hierarchies (Larson 2005, Nygren 2005). Agrawal and Ribot (1999) and Agrawal and Gibson (1999) classify powers transferred through CBFM into three categories: legislative, executive, and judicial. These are, in turn, translated into three empirically examinable categories: (i) the power to create rules about the use of the resource, (ii) the power to implement rules, and (iii) the power to adjudicate disputes. This framework covers the three institutional mechanisms of power transfer, which we have found suitable for examining policy provisions and the practice of CBFM, especially when they are not necessary driven by local demands, and instead largely driven by external agents such as civil societies and donors and implemented through formal policy changes such as forest law.

The nature of institutions and actors are deemed fundamental for representation to occur with democracy identified as the key mechanism to ensure it. This suggests that the actors to whom power is transferred should be democratically elected (Ribot 2004, Larson 2005). Democratically elected actors are seen to carry the mandate of wider populations (Larson 2005); elections are seen as the mechanism for sanctioning leaders both positively, through election and re-election, and negatively, through nonelection, thereby providing a mechanism for local citizens to hold their leaders accountable (Larson 2005). Representation is also interpreted in both descriptive and substantive forms, where descriptive form refers to the number of members of a particular group elected, whereas substantive form refers to the representation of specific interests of that group (Wängnerud 2009, Bandiaky-Badji 2011). This distinction is important because it is possible for members of a group to be elected but not represent the interests of that group. For example, women elected to male dominated institutions may not necessarily represent women's interests; they may even conform to a male stereotype. Deficiencies in representation may be a mechanism through which some actors are disenfranchised. On the other hand, it could be positive for people whose asset-based agency is low, such as the poor, low castes, and other marginalized groups who may be empowered through deliberative processes within institutions to promote their interests.

Therefore, in addressing questions about CBFM and its effects on empowerment it is necessary to look into (1) whether there is a genuine transfer of powers from one level of government to another, (2) whether power is transferred to local institutions that are representative, which is understood as being responsive to the needs of different segments of the local community, but also (3) whether this transfer will actually lead to reconciliation of multiple, and sometimes conflicting, interests of socially and economically differentiated actors (Nygren 2005).

\section{METHODS}

Ngare Ndare Community Forestry Association/Trust

Ngare Ndare forest covers an area of 5500 ha $\left(55 \mathrm{~km}^{2}\right)$ across an interface of humid and dry ecosystems in Meru and Laikipia Counties in north-central Kenya. It is a public forest, gazetted in 1932 by the colonial government. It is managed by the KFS in conjunction with the local CFA/Trust. Ngare Ndare CFA started as a working group in the year 2000. A working group is a legally recognized institution that operates as a forum for stakeholders, including individuals and organizations, on a matter of common interest, in this case, forest management. The working group was formally registered as a Trust in 2004. A trust is an institution registered under the Law of Trusts, where people named as Trustees manage property, in this case the forest, on behalf of the beneficiaries, in this case the local community (GoK 2012). When the Forest Act was passed in 2005, it obliged communities and 
any pre-existing organizations to register as CFAs to apply to KFS to comanage state forests. The Ngare Ndare Trust was registered as a CFA in 2007, but the original Trust remained the predominant local institution. The CFA and the Trust are separate legal entities, but they actually operate as one and the same institution in practice.

The highest decision-making organ of the CFA/Trust is the board of trustees, comprising nine members: one elected chairman from each of the six village community-based organisations (CBOs), two appointed representatives of the conservancies, and one appointed representative of the medium and large-scale farms. The local forester and the manager of the Trust were ex-officio members of the board, which meant that they could provide suggestions to the board, but had no voting rights.

Ngare Ndare CFA/Trust forms a good case for studying representation and empowerment. It has been in existence for a while (since 2004 when the Trust was formed and 2007 when the CFA was registered). It also fulfills the formal criteria set up by the KFS as a precondition for engaging in CBFM. This includes the preparation of a management plan, and signature of a management agreement. At least in formal terms, the Ngare Ndare CFA embodies a CFA as envisioned by the Forest Act. Finally, the CFA is located in an area where the "local community" comprises different groups with distinguishable needs and interests in forest management.

\section{Data collection methods}

The primary data for this study was collected between September and November 2012 and February and June 2013. The research took place at two levels: a national level policy review and a local level field research. The national level study included a critical review of legal and policy documents including the Forest Act of 2005, Participatory Forest Management (PFM) guidelines, and PFM rules. This was combined with 15 key informant interviews involving actors from KFS, the Ministry of Environment, Water and Natural Resources, and civil society organizations including the Forest Action Network, Kenya Forests Working Group, and National Alliance of Community Forest Associations (NACOFA). The aim of the interviews was to gain a broad view of the extent to which forest management had changed since the introduction of CBFM; the requirements for community participation within CBFM and the options and challenges faced by CFAs; as well as how the legal provisions such as the Forest Act and the subsidiary legislation influenced local empowerment associated with CFAs. It was important to acquire insights at this higher (national) level because the challenges and options explained here, such as limitations of empowerment of CFAs by legal provisions, helped in interpreting the findings of the subsequent case study.

The local level field research included a study of the six villages and the four medium and large-scale farms in the jurisdiction of the Ngare Ndare CFA. We aimed to collect data on the types of powers devolved to the CFA and to examine representation within the CFA. We therefore employed a combination of interviews, focus group discussions (FGDs), and a semistructured survey to collect data from the various groups of actors. We conducted a total of 15 semistructured interviews with leaders of the studied CFA, CBOs and user groups, and other community leaders including chiefs. These respondents were purposively selected to explain the local organization of the CFA: who was part of it and how they came to be there, the rules of forest access, who formed them and what power there was to enforce them, and the roles and benefit sharing arrangements relating to the CFA and KFS. We conducted six FGDs in each of the six villages to understand the dynamics of representation, that is, how the villagers selected their leaders, to what extent their interests with regard to forest access (their roles and benefits), were represented within the CFA and to what extent different actors were involved in making and implementing various rules and solving resulting disputes. Qualitative data were systematically analyzed following the constant comparison method (Glaser and Strauss 2009). This involved coding, achieved by creating broad categories from interview and FGD responses and the content of policy instruments, refining these categories into subthemes using more concrete rules, and then building a grounded theory set out in the results, that drew on the researchers' first-hand experience with the setting, informants, and documents.

Finally, we conducted intra-household surveys in two villages. The survey was administered to 120 randomly selected households within the two villages, by applying a set of randomly generated numbers to a list of households obtained from local leaders. The survey aimed at providing key socioeconomic characteristics of the households such as land ownership, ethnicity and forest access. These data were processed using the Statistical Package for Social Science (SPSS) and descriptive statics used to quantify ownership and access amongst different groups of respondents. It enabled us to generalize household variables and triangulate responses with qualitative data collected through interviews and FGDs; it was not aimed at drawing statistical comparisons amongst villages.

\section{Socioeconomic characterizations of the respondents}

Ngare Ndare CFA covers six villages, two medium-scale farms, one large-scale farm, and two large-scale conservancies surrounding Ngare Ndare forest. Each of the six villages has a registered community-based organization $(\mathrm{CBO})$, which represent the village at the $\mathrm{CFA}$ level. The $\mathrm{CBO}$ in turn comprise self-organized user groups that include: water, grazers, beekeepers, firewood collectors, tree planters, and young people, based on various access and usufruct rights. The six villages are occupied by smallholder farmers generally with up to 2 ha, medium-scale farms with 50-100 ha, and large-scale farms and conservancies with more than 10000 ha (Table 1).

Land tenure differentiations (sizes and usage of land at household level) largely structured the different groups who accessed the forest and formed the CFA. Smallholder farmers in Ngare Ndare were mainly ethnic Africans, who practiced agro-pastoralism. They grew crops such as maize and vegetables for household consumption and sold the surplus in the Timau and Nanyuki urban centers. Some smallholder groups such as the Maasai, Samburu, and Turkana tended to be more pastoralist-oriented; they kept large numbers of livestock, whereas the Meru and Kikuyu were more farming oriented with fewer livestock and more of a focus on crop cultivation. These groups' use of forest was commensurate with their livelihood strategy, with the majority of the Maasai indicating that they depended on the forest for grazing rather than farming, whereas the Meru, Kikuyu, and other farming groups indicated that they depended on the forest 
Table 1. Selected socioeconomic characteristics of respondents and their access to various forest products (Source: Survey data and focus group discussions).

\begin{tabular}{|c|c|c|c|}
\hline & Land sizes & Ethnicity & $\begin{array}{l}\text { Main forest products accessed and } \\
\text { interests }\end{array}$ \\
\hline Smallholder farmers $(n=120)$ & $\begin{array}{l}<50 \text { ha; } \\
91 \% \text { had } 0-2 \text { ha }\end{array}$ & $\begin{array}{c}\text { Africans } \\
\text { Kikuyu }(22 \%) \\
\text { Maasai }(30 \%) \\
\text { Meru }(34 \%) \\
\text { others (Turkana, Samburu, \& } \\
\text { Borana; } 14 \%)\end{array}$ & $\begin{array}{c}\bullet \text { Firewood } \\
\text { - Water for domestic use and } \\
\text { irrigation } \\
\cdot \text { Grazing }\end{array}$ \\
\hline Medium farm holders (2) & $50-100$ ha & Europeans & - Water for irrigation \\
\hline Large scale farm holders (1) & $>10,000$ ha & Europeans & - Water for irrigation \\
\hline Large scale conservancies (2) & $>10,000$ ha & Europeans & $\begin{array}{l}\text { - Wildlife habitat conservation } \\
\text { • Eco-tourism }\end{array}$ \\
\hline
\end{tabular}

for irrigation water more than for grazing. Both groups depended on the forest for firewood collection, construction wood, gathering of medicinal plants, and beekeeping.

People of European descent whose families settled there during colonial times owned medium-scale farms, large-scale farms, and conservancies. They practiced mechanized farming or wildlife conservation and tourism. The farmers grew wheat, vegetables, and flowers, mainly for export, while the conservationists practiced high-end tourism mainly catering for international visitors. The farmers used the forest mainly as a supply of water for irrigation, while the conservancy owners relied on the forest as a habitat connector between their private conservancies, public forest nearby, and other ecosystems in the area, such as Mt. Kenya.

\section{FINDINGS}

\section{Transfer of powers}

Using the framework outlined in Figure 1, we investigated transfer of powers in three categories: (a) the power to make rules, (b) the power to implement and enforce the rules, and (c) the power to resolve disputes arising from implementation of the rules. From the data we obtained, we further classified "rules" into four categories: (i) forest conservation rules, which included designating forest areas for conservation versus utilization and tree planting; (ii) harvesting rules, which included those governing grazing, firewood collection, beekeeping, water, and other forest products and services; (iii) protection rules, which included firefighting, guarding and control of illegal activities; and (iv) benefit sharing rules. Although we discuss the first three subcategories of rules (conservation, harvesting, and protection) together, we separate them in our presentation below from the benefit sharing rules because the latter were the main concern of the management agreements signed between KFS and CFAs.

\section{Power to make rules}

There are no provisions for CFAs to make rules either in the Forest Act, or in other subsidiary legislation. The Act vests these powers on KFS and the Minister of Environment, Water and Natural Resources. The Forest Act (4d) broadly states the functions of the "service" as "formulating policies and guidelines regarding the management, conservation and utilization of all types of forest areas in the country"; while $59(1 \& 2)$ vests the power to make all forest conservation, utilization, and protection rules on the minister. According to the national level interview respondents (Key Informant $[\mathrm{KI}] 4,5,6^{[3]}$ ), only state actors, including the Ministry for Environment, Water and Natural Resources (MEWNR) and KFS, had the power to make the rules. The ministry made rules controlling timber harvesting, charcoal burning, and grazing at the national level, which then determined who could access these resources at the local level. The minister also periodically issued and lifted nationwide bans on these activities to control forest utilization. However, the same respondents also indicated that these bans were often ineffective in controlling the activities at a local level. For instance, charcoal burning was legalized under new regulations in 2009 precisely because previous bans had resulted in an escalation of charcoal prices fuelling increased illegal production (KI 6).

In Ngare Ndare, CFA leaders (Semistructured Interviews [SSI] 7, 8 ) indicated that all rules of access and determination of access fees for forest products were crafted by KFS. Harvesting of forest products was also indirectly controlled through the number of licensed collectors by the local forester employed by KFS. Those who could afford the fees could collect the products legally, while those who could not afford fees could only collect them illegally.

FGDs with smallholders revealed that the CFA could have negotiated for some power to make basic rules before signing the management agreement with KFS (FGD 1, 3, 5, 6). The rules mentioned included making decisions on whether or not to charge forest access fees under the management agreement. They discussed how the management agreement provided an opportunity to negotiate some of the legal powers held by the state, and control over benefits to communities. They explained, however, that these powers had not been transferred to the CFA because some powerful groups (medium-scale and large-scale farms and conservancy owners) were in favor of smallholders being charged access fees and their access to the forest being restricted to conserve the forest (FGD 1, 3, 5, 6).

Power to implement and enforce rules

The Forest Act vests the power to enforce forest rules on forest officers, defined as "a forester, a disciplined officer of the service, or an honorary forester" (GoK 2005:part V). The Forest Act however allows CFAs to apply to participate in forest monitoring and enforcement of forest protection rules (GoK 2005: article 45, 
e, iii). In Ngare Ndare, the CFAs enforced as well as implemented the rules formulated by state authorities. For instance, FGDs revealed that through the management agreement signed with KFS, the CFA was obliged to control forest activities that would lead to forest degradation, including forest fires, overgrazing, and tree cutting. The CFA enforced these rules through the respective user groups and rangers employed by the Trust, who arrested and/ or reported offenders to local leaders. The entire forest was policed by a total of 17 rangers: three employed by KFS and 14 employed by the Trust (FGD 1, 2, 3, 4, 5, 6). The big disparity in the number of KFS versus Trust rangers is indicative of the major burden of forest protection falling to the CFA/Trust. Rangers employed by KFS mainly collected fees and issued permits for grazing and firewood collection; while those employed by the Trust did not collect any revenue, but were mainly conducting patrols to ensure compliance with the rules and the arrest of offenders (SSI 1, 2).

Almost $85 \%$ of our survey respondents indicated that illegal activities such as charcoal burning and logging, as well as the incidence of fire had greatly reduced since the Trust/CFA had started enforcing the rules. This was attributed to the increased monitoring by the rangers and internal monitoring by community members, who would report each other to local leaders. User groups also had internal self-regulatory rules. For instance, the grazers user group carried out rotational grazing in designated paddocks (grazing areas), reported ingression to the forest by outsiders and monitored pasture regeneration to avoid overgrazing. They also restricted grazing of goats in the forest because their browsing was thought to cause forest degradation. Some rules that the CFA was expected to implement, like controlling excess use of water, were made difficult to enforce because of competition for water within and amongst different groups, which often required alternative dispute resolution (SS 2, 4). For instance, following water-related conflicts, the water-user groups had commissioned a study to monitor how much water smallholders, medium- and large-scale farms, and flower farms nearby abstracted in the year 2012, to arrive at equitable water distribution amounts and charges (SSI 15).

\section{Power to resolve disputes}

The PFM guidelines require any stakeholders, government, NGOs, religious groups, or the private sector, working with CFAs to train the CFAs in conflict management and negotiation skills. However, neither the formal policies, nor the management agreement, specifically mention the devolution of judicial roles, or the sharing of responsibility between KFS and CFAs. As such, it remains unclear how conflicts should be handled.

In practice, FGDs revealed that the Trust/CFA in Ngare Ndare had not received any formal training on conflict resolution, but that it successfully handled disputes, such as those involving grazing, and inclusion or exclusion of outsiders, particularly during the dry season. Resolutions were made under the oversight of the local KFS forester and other local leaders, such as village chiefs. Minor offenders, such as women harvesting forest products without licenses were arrested by the forest guards and presented to the local forest office where they were either fined or given a verbal warning by the forester. Major offenders, such as illegal loggers, were arrested and taken to court, where they were subjected to a more thorough judicial process. When disputes amongst parties, such as conflicts over water access, could not be resolved by the CFA because of vested interests of various actors in the institution itself, other actors, including water users associations, chiefs, and other relevant government authorities, would become involved (SSI 4, 13, 15). FGDs also indicated that disputes would be subject to court processes if they escalated beyond what could be handled through local dispute resolution mechanisms.

\section{Benefit sharing rules}

The Forest Act and subsidiary legislation did not specify how benefits would be shared between CFAs and KFS. In the absence of national benefit sharing rules or a national framework, the roles, benefits, and responsibilities of each actor were determined by the management agreement, signed between the CFA and KFS at the onset of CBFM (KI 1, 3, 4). In Ngare Ndare, the management agreement entitled the CFA to benefits accruing from eco-tourism, which included charging entry and camping fees to local and international visitors to the forest (SSI 3, 6). KFS on the other hand, took the revenue from grazing, firewood and water access fees, as well as other licenses issued (FGD 1, 6; SSI $3,6)$. The CFA revenue increased significantly over the three-year ${ }^{[4]}$ collection period to approximately US\$6000 in 2010, $\$ 24,000$ in 2011 , and $\$ 38,000$ in 2012 , outstripping the revenue collected by KFS (see Chomba et al., in press). In addition, the CFA was required to remit an annual ecotourism concession fee of KSh 1.2 Million (approx. US\$15,000) annually to KFS (SS1 2, 6). The net revenue that the CFA/Trust collected from eco-tourism was reinvested in paying for conservation activities, such as salaries of guards to police forest access by smallholders (SSI 4, 15).

Overall, KFS transferred the power to execute rules to the CFA, but maintained the power to craft these rules. Dispute resolution powers were not well defined but in practice distributed among formal and informal structures at local level, with opportunities for more formal legal redress if they could not be solved locally. KFS also maintained its revenue collection from local communities in respect of their access to basic livelihood needs such as grazing, firewood, and water, even though it was the communities themselves who largely protected the forest through internal policing and from ingress by external actors. The combination of these rule-making powers by state authorities, and the devolution of executing roles to the CFA, resulted in local perceptions of only partial decentralization with control of forest management still largely resting with the state. The head of an NGO that had been prominent in spearheading community forestry in Kenya stated emphatically the following:

... there is no decentralized forest management in Kenya. All decisions about government forests are made at the KFS headquarters, including minor ones, like who should be invited to a forest meeting; who should harvest a load of firewood or graze their goats and cows, let us say, at Mt. Elgon forest. (KI 9: 16.10.2012)

The Trust/CFA was a critical institution where the exchange of power and benefits were negotiated between state agencies and local communities. The CFA was also composed of different segments of the community.

How did the CFA represent the interests of various groups? The intra-household surveys and interviews with local leaders revealed two key dimensions of representation elaborated (cf. Fig. 
1): (i) descriptive representation in terms of the numbers of people from different groups who were members of the Board of Trustees (the decision-making organ of the CFA) and the modality for choosing them; (ii) substantive representation, in terms of responsiveness to competing needs and interests of different groups.

With regard to descriptive representation, the modality of choosing members of the board of trustees was that each of the six village CBOs elected their officers, chairmen, treasurers, and secretaries, every 3-4 years. The six CBO chairmen and three representatives of the medium-, large-scale farm, and conservancies then formed the board of trustees (FGD 1, 2, 3, 4, $5,6)$. The representatives of the medium- and large-scale farms were the actual owners of the farms who appointed, or as they termed it themselves, volunteered to assume these positions (SSI 14, 15). So, according the to the FGDs, although the local communities could remove their own representatives at least every 3-4 years if they did not address their needs, there was no mechanism to remove the representatives of the medium- and large-scale farms from their positions.

The nine members of the board of trustees internally appointed the chairman of the board (SSI 2,14, 15). The present chairman, one of the medium-scale farm owners, had held the post since the formation of the trust in 2004 (SSI 2). The constitution of the CFA, seen by the main author and collaborated by interview respondents (SSI 2, 4), allowed him to hold office for a maximum of two consecutive terms, each term running for four years. Although his second term ended in 2012, he was still in office in 2013. No internal elections had been convened by the board, which smallholders and other $\mathrm{CBO}$ chairmen considered an indication of an attempt by the large-scale farmers to hold on to power (FGD 1, 3, 4; SSI 2, 11).

In numerical terms, the six CBO chairmen, if united, could prevail over board decisions via garnering a majority of votes (SSI 2, 10, 11). In practice, however, the agency of board members varied, with the few wealthy medium- and large-scale farmers and conservancy owners able to exert greater influence (SSI 2). The $\mathrm{CBO}$ chairmen stated that by the virtue of being registered as the legal trustees of Ngare Ndare Trust, as well as because of their socioeconomic position related to their extensive property and other endowments, the medium- and large-scale farmers and conservancy owners were viewed by the community as both powerful and benign to the point of not being challenged. This was so even when they made unpopular decisions, such as retaining their chairman in office, beyond the maximum term (SSI $2,10,11)$. One village leader summed up the situation as follows.

Even though we are numerically more ... the Trust is controlled by the large-scale farmers, because they provide funding for it through donations and offer other kinds of support ... they supply vehicles for ferrying other members from the villages to the trust office during meetings, advertise eco-tourism activities in the public forest to high end visitors in their lodges, thereby increasing the revenue of the trust, mobilize partnerships with private corporations such as Safaricom, the British Army [which has a large training facility nearby], and others, to raise funds for conservation and the local communities, and also support development activities in the wider community such as mobile health clinics and granting education bursaries for needy children. (SSI 13: 10.10.2012)

The conservancy owners were also founders and sitting board members in other regional conservation organizations such as the Northern Rangeland Trust and Laikipia Wildlife Forum through which they influenced conservation decisions in the larger ecosystem (SSI 8, 14). Thus, they were regarded in the community as powerful, and their decisions at the CFA board of trustees level were rarely questioned (SSI 2, 10, 11). The dependence on largescale farmers and conservancies by the Trust/CFA and, by extension, the wider community, was also explained by smallholder farmers and their representatives, some of whom stated they did not wish to upset their relationship (FGD 5; SSI 10).

The board of trustees allocated the revenue collected from ecotourism, as well as other revenues such as donations from corporations or well-wishers, to various kinds of expenditure (SSI $2,8,14)$. During the signing of the management agreement, the Trust had promised the community that the revenue would be shared on a 60 by 40 ratio to community development and the running costs of the CFA, respectively (FGD 1,2, 6). In practice, the Board had overruled this and allocated most of the revenue to the trust's running costs, which included salaries for the 14 forest guards, a manager and accountant, and fueling and maintenance of patrol vehicles (SSI 2, 8, 10). It was not until March 2013, after the six CBO chairmen insisted that the villagers needed to see some benefit from managing the forest, that the board allocated modest sums (KSh 50,000, approximately US\$600) to each village for them to allocate to various projects (FGD 1, 2, 3, 4, 6; SSI 2, 9, 10). As a result of this type of decision making, local communities had come to perceive the Board of Trustees as being under the control of the large-scale farmers and conservancy owners, and to act in favor of conservation, as opposed to livelihood enhancing activities (FGD 1, 2, 3, 4, 6)

FGDs and household surveys revealed that smallholders mainly accessed extractive forest products, such as fodder or grazing, firewood, water for irrigation, and honey that were important for their livelihoods. Although the smallholders indicated the need to protect the forest for the supply of these products in future, they perceived that KFS was interested in extracting fees, supported by medium- and large-scale farmers, whose forest needs were mainly conservation for wildlife, as well as a source of water for irrigation.

FGDs and interviews with $\mathrm{CBO}$ leaders further revealed how these competing needs and interests compelled large-scale farmers to support actions by KFS that were not in the interests of smallholders. The smallholders, among other things, argued that large-scale farmers were in favor of the agency charging them fees for access to grazing, firewood collection and other resources from the forest, even though the agency bore hardly any of the costs of protecting the forest (FGD 1, 2, 6). Smallholders paid KSh 16 (US\$0.19) per sheep per month and KSh 50 (US\$0.59) per cow per month for grazing. Firewood permits were issued at KSh 100 (US\$1.18) per back or head load per month, while water access was charged by KFS at the point of extraction if this was inside and the local water agency charged per unit of consumption at the household level (FGD 1, 2,6). The revenue from firewood 
and grazing was collected by the forester and was supposed to be remitted to KFS headquarters, although various respondents frequently mentioned cases of corruption (SSI 2, 10, 14).

Some respondents indicated that the fees charged for access to grazing and firewood collection were high and unnecessary, particularly considering that the fees were collected by KFS and were not used to benefit the local community (FGD 6; SSI 4, 10, 11). On the other hand, conservancy representatives had diverted resources from an agreed 60 by 40 ratio to allocate revenue mainly for forest protection. One CBO chairman noted as follows.

\begin{abstract}
...KFS has no real costs as the CFA has taken over the role of forest protection. The CFA employs 14 guards compared to the 3 guards employed by KFS. All the revenue collected by the CFA from ecotourism was previously spent on fueling the vehicle for patrols and paying salaries for the guards. The wazungus [white large-scale and medium-scale land owners) on the board have championed the use of this money for forest protection. It was not until last year that we [chairmen of the six CBOs] managed to convince them that the communities would soon be fed up of protecting the forest without realizing any financial benefit. So they agreed we allocate KSh 50,000 (approx. US\$600) for each village to carry out some developments... (SS1: 12.10.2012)
\end{abstract}

In summary, the powerful medium- and large-scale farmers and conservancy owners, appeared to have captured the CFA/Trust and diverted it in favor of their interests, even in the presence of six CBO chairmen elected by the majority of smallholders. On the other hand, KFS extracted revenues through forest access fees and ecotourism concession fees from the smallholders, while delegating forest protection, conservation, and rule enforcement through the CFA.

\section{DISCUSSION}

\section{Implications of CBFM for community empowerment}

Our findings show that overall, the introduction of the Kenyan Forest Act of 2005 and implementation of CBFM in Kenya signify a major shift away from state-centric forest management that has prevailed over the last century. Policy documents, including the Forest Act and other subsidiary legislation that we examined contained clear statements that envisioned a goal of local empowerment. The legislation required CFAs to be representative of interested stakeholders, while taking into consideration marginalized groups. However, the same laws and policies retained the power to make and enforce rules with state authorities, mainly KFS and the environment ministry, and their local antennas. In practice, enforcement was largely delegated to CFAs.

Our examination of how the process of local empowerment played out through implementation of CBFM in Kenya reveals two major reasons why outcomes fall short of expectations. First, local empowerment was undermined by institutional structures, including policies and actions of state actors that limited transfer of powers to CFAs. Second, pre-existing social and economic inequality coupled with competition for environmental goods and services amongst different groups at the local level prevented marginalized groups from exercising sufficient agency to achieve effective representation and influence in the CFAs. These two constraints re-enforced each other. Thus, because of their lack of agency, the marginalized groups could not influence the contents of the management agreements between the CFA and KFS. Instead of a transfer of power in favor of the marginalized groups, the management agreement ended up not only serving, but actually reinforcing the power of larger farmers and conservancy owners.

In terms of the institutionally generated opportunity structures, we found that the powers transferred to CFAs were unbalanced, in that power to execute rules was transferred without requisite power to make or alter them (Agrawal and Gibson 1999, Agrawal and Ribot 1999). The state agency retained the powers to make rules regarding forest use, access, and distribution of revenue. In practice the state had devolved responsibilities to implement rules but not the discretionary powers to determine and change them, or sufficient financial incentives to implement them. The power to resolve disputes was distributed amongst a number of local institutions and actors. The mix of powers that ideally should be devolved under CBFM remains contentious but many authors suggest that it should follow the principle of subsidiarity, that is, that decisions are made at the lowest possible level without compromising functionality at higher levels, while paying attention to a balance between costs and benefits (Føllesdal 1998, Ribot 2003). In the empirical case examined, the local and national level institutions of the central state had retained rulemaking powers and economic benefits, preventing the achievement of its stated goal of local empowerment.

With respect to asset-based agency, wealthy local elites, whose needs and interests in managing the forest did not match those of the majority of poor smallholders and other marginalized groups, took up appointed positions in leadership of the CFA board (descriptive representation), to influence decisions that furthered their own interests (substantive representation). This reveals a form of elite capture through representation. Our findings further reveal that the CFA could have negotiated for more decisionmaking powers and control over economic benefits before signing the management agreement with KFS, on the basis that selfpolicing through the CFA released KFS from incurring significant costs for forest protection. However, the prospect of negotiating for greater powers was undermined by competing claims and interests of the two key groups in the CFA/Trust, with those of the more powerful group prevailing. The management agreement ended up obliging smallholders, who already started out with limited assets, to pay access fees to KFS for their extractive needs while contributing to the forest protection that largely benefited larger farmers and conservancy owners. The resulting institutional structure of the CFA thereby further undermined their agency-based empowerment, with respect to their ability to take control over their lives and secure better livelihoods (Alkire 2005, Cleaver 2005). These dynamics, whereby social and economically differentiated groups compete for environmental goods and services, and one group acts to limit access of the other, have been repeatedly observed elsewhere (Nygren 2000, SaitoJensen et al. 2010).

In relation to the wider debate on empowerment, our study is also consistent with previous authors who have shown that the processes of local empowerment through CBFM are usually 
neither effective nor well achieved in practice (Agrawal and Gibson 1999, Poteete and Ribot 2011). There are several explanations generally advanced for this. At a policy level, legislative frameworks governing the introduction of CBFM are often faulted, as in our case, for allocating insufficient powers to local communities (Ribot et al. 2006, Agrawal and Ostrom 2008). Policies have also been criticized for appearing to apply double standards, in maximizing profit extraction through strict oversight by the state, while claiming to be propoor (Oyono 2004, Larson and Ribot 2007). Policies are also seen as blind to the diverse and dynamic local context within which they are applied, ultimately falling short of achieving the goal of local empowerment.

In other cases, as in Ngare Ndare, powerful actors use various means to attenuate the process of local empowerment, despite the existence of potentially empowering policies. These behaviours can be classified as economic, political, discursive, coercive, or symbolic (Poteete and Ribot 2011). In our case, economic and symbolic forms of power were wielded by larger scale farmers and conservancy owners, who not only controlled the CFA, but were also major players in other local development initiatives, including provision of health and education services to the local community. In this case, if the poorer group challenged power structures, they might have to face opportunity costs of acting against the interests of the elites. These power imbalances may hold back poorer groups from holding the CFA accountable, for fear of social and economic repercussions, thereby reinforcing their position of disempowerment (Cleaver 2005). This reduces the overall ability of smallholders to negotiate, influence, control, and hold institutions accountable (Narayan 2005). Although some scholars have shown how institutional forms of empowerment, including representation and the ability to hold leaders accountable, are undermined by elite capture (SaitoJensen et al. 2010), others have looked at the positive side. They show that elites may provide resources, networks, and knowledge that can be useful for supporting local development (Olowu 2003), and that elite capture is not always a permanent outcome because formalized structures under CBFM may expose domination by elites, which might then be challenged by marginalized groups (Saito-Jensen et al. 2010).

\section{CONCLUSION}

Our research shows that although CBFM policies may contain bold statements about local empowerment, in practice, they may easily fall short of achieving it. In Ngare Ndare, we attribute this to insufficient and unbalanced transfer of powers to local institutions, coupled with elite capture and structural biases produced over time. The state transferred responsibility for enforcing rules but not powers to make them, or the revenue from their implementation, and did not ensure local institutional structures that allowed the majority of smallholder farmers to exercise agency. State actors, including the Kenya Forest Service, retained legislating and regulating access and use of forest products. Economic benefits, including fees charged for accessing forest products, were also largely retained by KFS, while CFAs only received revenue from eco-tourism. For CBFM institutions to contribute to local empowerment, governments and their agencies must devolve rule-making powers, so that CFAs have decision-making powers and economic benefits commensurate with their responsibility for forest protection. This would conform to the principles of subsidiarity, where actors with responsibility for implementing forest rules are also enabled to make decisions about forest utilization, protection, and revenue.

When more powers are transferred, measures to ensure equitable representation in the local institutions exercising these powers become more important. Particular measures may be required to ensure that disadvantaged groups can exercise sufficient agency within the institutional structures that are set up. This requires going beyond a focus on descriptive representation, in terms of prescribing numbers of elected leaders from various groups, to ensuring substantive representation, in terms of responsiveness of institutions to a diverse set of constituents, with differing and sometimes conflicting needs and interests. Careful considerations should be made in crafting institutions that ultimately empower the socially and economically marginalized groups and circumvent elite capture. Election of a majority of local leaders does not seem to eliminate elite capture because elites have the resources and social capital to get elected, or assume appointed positions from where they can exert great influence. Whereas CBFM by itself cannot easily address larger socioeconomic structures that create and sustain elites, governments can address inequity and poverty, created by heavily skewed distributions of land ownership and wealth. CBFM could contribute to addressing these issues if formalized rules were drawn up regarding equity in distribution of forest benefits.

More comprehensive valuation of forest benefits, including ecosystem services such as water, wildlife habitat, and ecotourism, should be taken into account in making rules on charging fees and benefit sharing, so that the beneficiaries of these ecosystem services share responsibility for forest protection along with those beneficiaries who rely on firewood collection and grazing. In that way, the large-scale farmers and conservancy owners, might realize that, apart from wanting to control CFAs to further their own interests, they share a burden of responsibility for ensuring benefits accrue to the larger number of poorer smallholders. Awareness of these challenges to achieving empowerment should foster design of more appropriate decentralization policies and practice guidelines and prompt governments to act on inequalities and poverty that stifle agency of marginalized groups, together with putting measures in place to make it more difficult for elites to capture local institutions to which power is devolved.

[1] These refer to public forests, which although are said to be managed by the state on behalf of the public, essentially means they would fall under state ownership (see Agrawal et al. 2008 on governance of world's forests).

[2] The "Nyayo tea zones" was a World Bank funded project in the 1980 s that aimed at creating $100 \mathrm{~m}$ buffer zones around forests where tea was planted as a "simple but effective way" of stopping people from encroaching government forests. This turned out into a major loss of forests and protracted ownership of the tea zones, which were grabbed by former president Moi, and his cronies (Klopp 2012).

${ }^{[3]} \mathrm{KI}$ and, later in the text, SSI numbers have replaced names of interview respondents. Focus group discussions are also labeled with numbers to enable tracing the origin of data sources.

${ }^{[4]}$ The CFA/Trust did not start collecting revenue until 2010 after KFS signed the management agreement and the CFA put up its human and technical infrastructure (including employing technical staff) together. 
Responses to this article can be read online at: http://www.ecologyandsociety.org/issues/responses. $\mathrm{php/7741}$

\section{Acknowledgments:}

We would like to thank the University of Copenhagen for providing the financial support that facilitated field research upon which this article is based. We also thank researchers under the Responsive Forest Governance Initiative who provided useful comments to the earlier drafts of the manuscript. Many thanks to two anonymous reviewers who provided useful insights that helped us improve this paper.

\section{LITERATURE CITED}

Agrawal, A., A. Chhatre, and R. Hardin. 2008. Changing governance of the world's forests. Science 320:1460-1462. http:// dx.doi.org/10.1126/science.1155369

Agrawal, A., and C. C. Gibson. 1999. Enchantment and disenchantment: the role of community in natural resource conservation. World Development 27:629-649. http://dx.doi. org/10.1016/S0305-750X(98)00161-2

Agrawal, A., and E. Ostrom. 2008. Decentralization and community-based forestry: learning from experience. Pages 44-67 in E. L. Webb and G. Shivakoti, editors. Decentralization, forests and rural communities: policy outcomes in South and Southeast Asia Sage, London, UK.

Agrawal, A., and J. Ribot. 1999. Accountability in decentralization: a framework with South Asian and West African cases. Journal of Developing Areas 33:473-502.

Alkire, S. 2005. Subjective quantitative studies of human agency. Social Indicators Research 74(1):217-260. http://dx.doi. org/10.1007/s11205-005-6525-0

Alsop, R., M. Bertelsen, and J. Holland. 2006. Empowerment in practice from analysis to implementation. World Bank, Washington, D.C., USA.

Bandiaky-Badji, S. 2011. Gender equity in Senegal's forest governance history: why policy and representation matter. International Forestry Review 13(2):177-194. http://dx.doi. org/10.1505/146554811797406624

Berkes, F. 2009. Evolution of co-management: role of knowledge generation, bridging organizations and social learning. Journal of Environmental Management 90:1692-1702. http://dx.doi.org/10.1016/ j.jenvman.2008.12.001

Blaikie, P. 2006. Is small really beautiful? Community-based natural resource management in Malawi and Botswana. World Development 34(11):1942-1957. http://dx.doi.org/10.1016/j. worlddev.2005.11.023

Borrini-Feyerabend, G., M. Pimbert, M. T. Farvar, A. Kothari, and Y. Renard. 2004. Sharing power: learning by doing in comanagement of natural resources throughout the world. IIED and IUCN/ CEESP/ CMWG, Cenesta, Tehran.

Brosius, J. P., A. L. Tsing, and C. Zerner. 1998. Representing communities: histories and politics of community-based natural resource management. Society \& Natural Resources 11 (2):157-168. http://dx.doi.org/10.1080/08941929809381069

Chomba, S., T. Treue, and F. Sinclair. In press. The political economy of forest entitlements: can community based forest management reduce vulnerability at the forest margin? Forest Policy and Economics. http://dx.doi.org/10.1016/j.forpol.2014.11.011

Cleaver, F. 2005. The inequality of social capital and the reproduction of chronic poverty. World Development 33 (6):893-906. http://dx.doi.org/10.1016/j.worlddev.2004.09.015

Føllesdal, A. 1998. Survey article: subsidiarity. Journal of Political Philosophy 6:190-218. http://dx.doi.org/10.1111/1467-9760.00052

Food and Agriculture Organisation of the United Nations (FAO). 2010. Global forest resource assessment 2010. FAO, Rome, Italy. [online] URL: http://foris.fao.org/static/data/fra2010/KeyFindingsen.pdf

Glaser, B. G., and A. L. Strauss. 2009. The discovery of grounded theory: strategies for qualitative research. Transaction, New Brunswick, New Jersey, USA.

Government of Kenya (GoK). 2005. Laws of Kenya, the Kenya Forests Act, 2005. Government Printer, Nairobi, Kenya.

Government of Kenya (GoK). 2012. Laws of Kenya, Trustee Act chapter 167, revised edition 2012 [1982]. Government Printer, Nairobi, Kenya.

Hardin, G. 1968. The tragedy of the commons. Science 162 (3859):1243-1248. http://dx.doi.org/10.1126/science.162.3859.1243

Ibrahim, S., and S. Alkire. 2007. Agency and empowerment: a proposal for internationally comparable indicators. Oxford Development Studies 35(4):379-403. http://dx.doi. org/10.1080/13600810701701897

Kellert, S. R., J. N. Mehta, S. A. Ebbin, and L. L. Lichtenfeld. 2000. Community natural resource management: promise, rhetoric, and reality. Society \& Natural Resources 13(8):705-715. http://dx.doi.org/10.1080/089419200750035575

Klopp, J. M. 2012. Deforestation and democratization: patronage, politics and forests in Kenya. Journal of Eastern African Studies 6(2):351-370. http://dx.doi.org/10.1080/1753105$\underline{5.2012 .669577}$

Larson, A. M. 2005. Democratic decentralization in the forestry sector: lessons learned from Africa, Asia and Latin America. Pages 32-62 in C. J. Pierce Colfer and D. Capistrano, editors. The politics of decentralization: forests, power and people. Earthscan/ James \& James, London, UK.

Larson, A. M., and J. C. Ribot. 2007. The poverty of forestry policy: double standards on an uneven playing field. Sustainability Science 2:189-204. http://dx.doi.org/10.1007/ $\underline{\text { s11625-007-0030-0 }}$

Leach, M., R. Mearns, and I. Scoones. 1999. Environmental entitlements: dynamics and institutions in community-based natural resource management. World Development 27(2):225-247. http://dx.doi.org/10.1016/s0305-750x(98)00141-7

Ministry of Environment and Natural Resources (MENR). 2007a. The forests (participation in sustainable forest management) rules. Government Printer, Nairobi, Kenya. 
Ministry of Environment and Natural Resources (MENR). 2007b. Participatory forest management guidelines. Government Printer, Nairobi, Kenya.

Mogoi, J., E. Obonyo, P. Ongugo, V. Oeba, and E. Mwangi. 2012. Communities, property rights and forest decentralisation in Kenya: early Lessons from participatory forestry management. Conservation \& Society 10(2):182-194. http://dx.doi. org/10.4103/0972-4923.97490

Mugo, E., C. Nyandiga, and M. Gachanja. 2010. Development of forestry in Kenya (1900-2007): challenges and lessons learnt. Kenya Forests Working Group, Nairobi, Kenya.

Narayan, D. 2005. Measuring empowerment: cross-disciplinary perspectives. World Bank, Washington, D.C., USA. http://dx.doi. org/10.1037/e597202012-001

Njeru, J. 2010. 'Defying' democratization and environmental protection in Kenya: the case of Karura Forest Reserve in Nairobi. Political Geography 29:333-342. http://dx.doi.org/10.1016/j. polgeo.2010.07.003

Nygren, A. 2000. Development discourses and peasant-forest relations: natural resource utilization as social process. Development and Change 31(1):11-34. http://dx.doi. org/10.1111/1467-7660.00145

Nygren, A. 2005. Community-based forest management within the context of institutional decentralization in Honduras. World Development 33:639-655. http://dx.doi.org/10.1016/j.worlddev.2004.11.002

Olowu, D. 2003. Local institutional and political structures and processes: recent experience in Africa. Public Administration and Development 23(1):41-52. http://dx.doi.org/10.1002/pad.258

Ostrom, E. 1990. Governing the commons: the evolution of institutions for collective action. Cambridge University Press, Cambridge, UK. http://dx.doi.org/10.1017/cbo9780511807763

Oyono, P. R. 2004. One step forward, two steps back? Paradoxes of natural resources management decentralisation in Cameroon. Journal of Modern African Studies 42:91-111. http://dx.doi. org/10.1017/S0022278X03004488

Poteete, A. R., and J. C. Ribot. 2011. Repertoires of domination: decentralization as process in Botswana and Senegal. World Development 39(3):439-449. http://dx.doi.org/10.1016/j. worlddev.2010.09.013

Ribot, J. C. 2003. Democratic decentralisation of natural resources: institutional choice and discretionary power transfers in Sub-Saharan Africa. Public Administration and Development 23:53-65 http://dx.doi.org/10.1002/pad.259

Ribot, J. C. 2004. Waiting for democracy. World Resources Institute, Washington, D.C., USA.

Ribot, J. C., A. Agrawal, and A. M. Larson. 2006. Recentralizing while decentralizing: how national governments reappropriate forest resources. World Development 34:1864-1886. http://dx.doi. org/10.1016/j.worlddev.2005.11.020

Ribot, J. C., J. F. Lund, and T. Treue. 2010. Democratic decentralization in sub-Saharan Africa: its contribution to forest management, livelihoods, and enfranchisement. Environmental Conservation 37(01):35-44. http://dx.doi.org/10.1017/s0376892910000329
Rowlands, J. 1997. Questioning empowerment. Oxfam, Oxford, UK. http://dx.doi.org/10.3362/9780855988364

Saito-Jensen, M., I. Nathan, and T. Treue. 2010. Beyond elite capture? Community-based natural resource management and power in Mohammed Nagar village, Andhra Pradesh, India. Environmental Conservation 37:327-335. http://dx.doi.org/10.1017/ $\underline{\mathrm{S} 0376892910000664}$

Sandbrook, C., F. Nelson, W. M. Adams, and A. Agrawal. 2010. Carbon, forests and the REDD paradox. Oryx 44:330-334. http:// dx.doi.org/10.1017/S0030605310000475

Standard Media. 2015. Kenya forest service signs 68 pacts with communities. 11 January. [online] URL: http://www. standardmedia.co.ke/business/article/2000147463/kenya-forest-servicesigns-68-pacts-with-communities

Standing, A., and M. Gachanja. 2014. The political economy of REDD+ in Kenya: identifying and responding to corruption challenges. U4 Issue 2014(3).

Thenya, T., B. O. B. Wandago, E. T. Nahama, and M. Gachanja. 2008. Participatory forest management experiences in Kenya (1996-2007). Kenya Forests Working Group, Nairobi, Kenya.

United Nations (UN). 1992. The statement of forest principles. Report of the United Nations Conference on Environment and Development, Rio De Janeiro, Brazil.

United Nations (UN). 2000. Millennium development goals (MDGs). UN, New York, New York, USA.

United Nations (UN). 2007. United Nations declaration on rights of indigenous people. UN, New York, New York, USA.

United Nations Economic Commission for Europe (UNECE). 1998. The UNECE convention on access to information, public participation in decision-making and access to justice in environmental matters. UNECE, Geneva, Switzerland.

Wängnerud, L. 2009. Women in parliaments: descriptive and substantive representation. Annual Review of Political Science 12:51-69. http://dx.doi.org/10.1146/annurev.polisci.11.053106.123839

White, A., and A. Martin. 2002. Who owns the world's forests? Forest tenure and public forests in transition. Forest Trends, Washington, D.C., USA.

World Bank. 2007. Strategic environmental assessment of the Kenya Forest Act 2005. World Bank, Washington, D.C., USA. 